\begin{tabular}{|l|l|}
\hline $\begin{array}{l}\text { Postprint } \\
\text { Version }\end{array}$ & 1.0 \\
\hline Journal website & $\underline{\mathrm{http}: / / \mathrm{dx} . d o i . o r g / 10.1016 / j . e j p a i n .2009 .05 .010}$ \\
\hline Pubmed link & $\underline{\mathrm{http} / / / \text { www.ncbi.nlm.nih.gov/pubmed/19540139 }}$ \\
\hline DOI & $10.1016 /$ j.ejpain.2009.05.010 \\
\hline
\end{tabular}

This is a NIVEL certified Post Print, more info at http://www.nivel.eu

\title{
Co-occurrence and associations of pain and fatigue in a community sample of Dutch adults
}

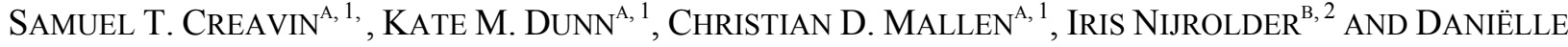 \\ A.W.M. VAN DER WINDT ${ }^{A, B,}$ \\ a Arthritis Research Campaign National Primary Care Centre, Keele University, Staffordshire ST5 5BG, \\ United Kingdom \\ ${ }^{\mathrm{b}}$ EMGO Institute and Department of General Practice, VU University Medical Centre, Van der \\ Boechorststraat 7, 1081 BT Amsterdam, The Netherlands
}

\begin{abstract}
Widespread pain and chronic fatigue are common in the general population. Previous research has demonstrated co-occurrence of syndromes that are associated with pain and fatigue (fibromyalgia and chronic fatigue syndrome), but there is limited existing data on the cooccurrence of these symptoms in general. This study investigates the co-occurrence of pain and fatigue, and characterises people with these symptoms individually, and in combination. A postal questionnaire was sent to a random sample of 4741 community dwelling Dutch adults registered with five general practices. There were 2447 participants (adjusted response $=53.5 \%$ ). Persistent fatigue was reported by $60 \%$ of the 451 subjects with chronic widespread pain. Chronic widespread pain was reported by $33 \%$ of the 809 responders with persistent fatigue. Anxiety and depression were more common in subjects who reported both symptoms than those who reported either one or neither. Participants who had chronic disease, high body mass index, low activity levels or did not perceive ability to influence health had higher adjusted odds of reporting both symptoms (but not one alone) than subjects not having these characteristics. Pain and fatigue occur more often than would be expected by chance and there are a number of reasons for this. Clinicians should be aware that co-occurrence of the symptoms is common, especially in people who have high BMI or chronic disease, and that people with both symptoms are often anxious or depressed. Further work should address longitudinal associations of pain and fatigue.
\end{abstract}

\section{INTRODUCTION}

Numerous studies have demonstrated that chronic widespread pain ([Croft et al., 1993], [Hunt et al., 1999] and [White and Thompson, 2003]) and fatigue ([Pawlikowska et al., 1994], [Lawrie and Pelosi, 1995], [Skapinakis et al., 2000] and [Reyes et al., 2003]) are common symptoms in the general population. These symptoms have a varying degree of severity, being most severe in their associated syndromes of fibromyalgia (Wolfe et al., 1990) and chronic fatigue syndrome ([Fukuda et al., 1994] and [Reeves et al., 2003]).

Individuals with fibromyalgia are often more tired than those without ([Hudson et al., 1992] and [Buchwald and Garrity, 1994]). Conversely people with chronic fatigue syndrome more often have fibromyalgia than people who do not have this condition (Jason et al., 2000). Co-occurrence of the more general symptoms of pain and fatigue is less well investigated. Some authors have reported higher levels of 
fatigue in subjects with pain ([Croft et al., 1993] and [Wolfe et al., 1995]), or that pain was more common in fatigued individuals ([Wessely et al., 1997] and [Njoku et al., 2007]), but a recent review could not identify studies reporting in more detail on the overlap of pain and fatigue in the community (Creavin, 2008). This is important as both symptoms influence quality of life ([Schweitzer et al., 1995] and [Aaron et al., 2002]), are associated with increased healthcare usage ([Hamilton et al., 2001] and [Kadam et al., 2005]), and psychological distress ([Wessely et al., 1997] and [Benjamin et al., 2000]). Having both symptoms may be more detrimental than one symptom alone.

Previous work has identified that pain is more often reported by individuals who are older ([Wolfe et al., 1995] and [Papageorgiou et al., 2002]) or female ([Croft et al., 1993] and [White and Thompson, 2003]). Additionally, subjects with widespread pain have higher levels of anxiety or depression ([Wolfe et al., 1995], [Hunt et al., 1999] and [Schochat and Raspe, 2003]). Similar associations of age, gender, anxiety, and depression, have been demonstrated with fatigue ([Skapinakis et al., 2000], [Hickie et al., 2002], [Bierl et al., 2004] and [Evengard et al., 2005]). Given this evidence, it is likely that these factors are also strongly associated with both symptoms in combination, although this has not been explored in depth. Less evidence exists for an association of pain or fatigue with lifestyle factors, such as high body mass index (BMI, [Kato et al., 2006] and [Schur et al., 2007], low activity levels ([Kroenke et al., 1988] and [Schur et al., 2007]), (co-morbid) chronic disease (Kenter et al., 2003) or self-efficacy ([Barry et al., 2003] and [Turner et al., 2005]). BMI, activity levels, chronic disease and illness perceptions are of interest because they are potentially modifiable, and while this is an epidemiological study, if an association exists, further work might explore a role for an intervention to modify these factors.

This paper aims to investigate the frequency with which pain and fatigue co-occur. Additionally, the association of BMI, activity levels, chronic disease and illness perceptions with reporting both symptoms will be explored.

\section{METHODS}

The sample for this analysis was participants in a large cross-sectional study conducted in the Netherlands (Van der Windt et al., 2008). A random sample of 4741 adults aged 18 years and over (approximately, 20\% of the sampling frame) was taken from the registration lists of five General Practices. Individuals who did not speak Dutch and a small number of patients with severe psychiatric disorders or serious or lifethreatening conditions (who were unfit to complete a questionnaire, or for whom the questionnaire would be too much of a burden) were excluded by General Practitioners (GPs).

\subsection{Data collection}

An information letter and self-completion postal survey was sent to the study sample. Non-responders were sent a reminder card two weeks after the initial questionnaire, on which they could indicate reasons for non-response. A further letter, with a new copy of the questionnaire, was sent after four weeks. The medical ethics review board of the VU University medical centre granted ethical approval.

\subsection{Measures}

The questionnaire asked about the presence of symptoms including fatigue and musculoskeletal pain lasting at least $24 \mathrm{~h}$ in the past month ([Pope et al., 1997], [Papageorgiou et al., 2002] and [Thomas et al., 2004]) and about GP consultation for these symptoms (yes or no) in the past 3 months. Pain was classified as being in the following locations: hand or wrist, elbow or arm, shoulder, neck, back, hip or knee, ankle or foot. In addition, responders were asked to indicate when the symptoms started (response options: less than 1 month ago, 1-3 months ago, 3-6 months ago, more than 6 months ago), how frequently the symptoms were experienced in the past 3 months and how often they caused limitations of work or daily activities (three response options: sometimes - about once per month, often - about 5 days per month, (nearly) always - more than half of all days). BMI was calculated using responders self reported height and weight. The survey had additional questions concerning age, sex, presence of a chronic disease (self-reported asthma, heart disease, diabetes, cancer, arthritis, fibromyalgia, any), and the frequency of physical activity (How often in the past 3 months did you exercise or carry out heavy physical work (in leisure time) lasting long enough to get sweaty, response options: less than once per month, about once per month, about two to three times per month, about one to two times per week, three or more times per week), which was analysed as less than weekly vs. weekly or more). The Hospital Anxiety and Depression Scale (Zigmund and Snaith, 1983) was used, with subscale scores of 8-10 for "possible" and more than 10 for "probable" anxiety or depression, as recommended by the instrument developers. Personal control was assessed using one item of 
the illness perception questionnaire (I believe I can influence my health, five response options including don't know: fully agree to fully disagree) (Moss-Morris et al., 2002).

\subsection{Definitions}

Table 1 presents the empirical definitions of pain and fatigue. All responders to the survey were categorised into one of four mutually exclusive pain categories. The definition for chronic widespread pain approximated the American College of Rheumatology definition (Wolfe et al., 1990), but subjects did not need to have pain in contralateral limbs, as this information was unavailable for the empirical analysis. Subjects who had pain lasting more than 3 months in each of upper limb (any of hand/wrist, elbow/arm, shoulder) and lower limb (any of hip/knee, ankle/foot) and axial pain (either neck or back) were classified as having chronic widespread pain.

\section{[TABLE 1.]}

Subjects with chronic widespread pain were further classified into those who were limited by their pain in two of the three anatomical sites on at least 5 days per month (classified as having limiting widespread pain, $\mathrm{CWP}+\mathrm{L}$ ) and those who were not limited by their pain to this extent (classified as having non-limiting widespread pain, CWP-L). Subjects who did not meet the criteria for CWP but reported pain in at least one of the seven locations (hand/wrist, elbow/arm, shoulder, neck, back, hip/knee, ankle/foot) lasting at least 3 months were classified as having chronic regional pain (CP) ([IASP, 1986] and [Macfarlane et al., 2008]). Subjects not meeting these criteria were classified as having no chronic pain. Subjects were included in only one group, which means for example, that although participants with $\mathrm{CWP}+\mathrm{L}$ met criteria for $\mathrm{CWP}-\mathrm{L}$ and $\mathrm{CP}$, they were analysed separately.

Additionally, all subjects were classified into one of three mutually exclusive fatigue groups. Many definitions exist in the literature, both for chronic fatigue, and chronic fatigue syndrome; this paper focuses on chronic fatigue. Chronic fatigue is often defined as fatigue that lasts more than 6 months, but this is not always the case ([David et al., 1990] and [Skapinakis et al., 2003]). In this study, to aid comparisons between chronic fatigue and chronic pain, chronic fatigue was defined as fatigue that lasted for 3 months or more. Subjects who reported fatigue in the last month and also fatigue lasting 3 months or more and occurring on at least 5 days per month were classified as having persistent fatigue ( $\mathrm{PF}-\mathrm{L})$. Subjects who were additionally limited by their fatigue on at least 5 days per month were classified as having limiting persistent fatigue $(\mathrm{PF}+\mathrm{L})$. All subjects not meeting these criteria were classified as having no persistent fatigue.

For analysis of the co-occurrence of the symptoms, subjects were again classified into one of four mutually exclusive groups but for this part of the analysis the limiting effect of the symptoms was not considered. Subjects with both CWP and persistent fatigue were classified as having both symptoms. Subjects with CWP but not fatigue were classed as having CWP only, subjects with persistent fatigue but not CWP as having fatigue only, and all others as having neither symptom.

\subsection{Analysis}

Cross-tabulations were used to examine the proportion of subjects with pain (chronic regional, CWP with and without limitations of daily life) who reported fatigue and the proportion with fatigue (with and without limitations) who reported pain. Results were further stratified by age and gender.

When examining differences in demographics between the subjects with different symptoms (neither, pain, fatigue, both), chi square tests were used to test statistical significance of findings across subgroups for categorical variables and ANOVA was used to test the null hypothesis that the mean for BMI and age was equal in all groups. Post hoc analyses using Bonferroni adjustment (dividing the significance level of $\alpha=0.05$ by the number of tests) was used to test which between-subgroup differences were statistically significant.

Odds ratios (ORs) with $95 \%$ confidence intervals $(95 \% \mathrm{CI})$ were produced using logistic regression to examine the association of reporting both symptoms with BMI $\left(<25 \mathrm{~kg} / \mathrm{m}^{2} \mathrm{vs} . \geq 25 \mathrm{~kg} / \mathrm{m}^{2}\right)$, activity levels (weekly vs. less than weekly), chronic disease and perceived ability to influence health (perceives ability vs. don't know vs. does not). Odds ratios were subsequently adjusted for age, gender, anxiety and depression. SPSS 14.0 was used for all statistical analyses. 


\section{RESULTS}

Completed questionnaires were returned by 2447 individuals, a further 171 blank questionnaires were sent back as a result of incorrect address or deceased addressee. The adjusted response rate was therefore 53.5\%. Demographics of the responders have been presented previously (Van der Windt et al., 2008). In brief, 58\% of responders were female and the mean (standard deviation) age was 49.9 (16.1) years. Approximately half of responders were overweight or obese, $8 \%$ perceived that they could not influence their health, $31 \%$ had a chronic disease and 50\% exercised less than weekly. Analysis of non-response suggested that nonresponders were more likely to be male and aged slightly younger than responders (Van der Windt et al., 2008).

Chronic regional pain was reported by 966 (39\%) of all 2447 responders. A further 451 individuals (18\%) reported chronic widespread pain, of whom 332 (14\% of all responders) were limited by their symptoms.

The prevalence of non-limiting persistent fatigue was $17 \%(n=404)$, and a further 405 responders $(17 \%)$ reported limiting persistent fatigue.

\subsection{Co-occurrence of symptoms}

Persistent fatigue was more common with increasingly severe pain, being reported by $18 \%$ of subjects with no chronic pain, $37 \%$ with chronic regional pain, $47 \%$ of those with CWP not limiting daily activities (CWP-L) and $64 \%$ of subjects with CWP that did limit daily activities (CWP+L).

Pain was more common in fatigued individuals than those without fatigue. Chronic regional pain was reported by $37 \%$ of subjects with no fatigue, $48 \%$ of those with persistent fatigue not limiting daily activities $(\mathrm{PF}-\mathrm{L})$ and $42 \%$ with persistent fatigue that did limit daily activities $(\mathrm{PF}+\mathrm{L})$. Similarly, $\mathrm{CWP}-\mathrm{L}$ was reported by $4 \%$ of persons with no fatigue, $7 \%$ with $\mathrm{PF}-\mathrm{L}$ and $6 \%$ with $\mathrm{PF}+\mathrm{L}$. The association was most marked for CWP $+\mathrm{L}$; this degree of pain was reported by $7 \%$ of subjects with no fatigue, $18 \%$ with $\mathrm{PF}-\mathrm{L}$ and $34 \%$ with $\mathrm{PF}+\mathrm{L}$.

When stratified by gender the results showed a similar pattern in men and women with fatigue occurring more often in women with pain than men. Chronic regional pain was reported by $49 \%$ of fatigued men and $43 \%$ of fatigued women, and CWP was reported by a further $30 \%$ of fatigued men and $34 \%$ of fatigued women. In both genders, persistent fatigue was reported more often by those with CWP $(55 \%$ of males, $62 \%$ of females) than those with chronic regional pain (31\% of males, $41 \%$ of females) (see Fig. 1).

\section{[FIGURE 1]}

When stratified by age approximately $45 \%$ of fatigued individuals in each age group reported chronic regional pain. In contrast CWP was reported by $22 \%$ of the fatigued young persons ( $<40$ years), $36 \%$ of the fatigued middle aged (40-60 years) and $44 \%$ of the fatigued older persons ( $>60$ years). Fatigue was reported more often by young persons with pain $(45 \%$ of those with chronic regional pain and $71 \%$ with CWP) than middle aged (37\% of those with chronic regional pain and 59\% with CWP) or older people (31\% with chronic regional pain and 53\% with CWP) (see Fig. 2).

\section{[FIGURE 2]}

Table 2 shows the characteristics of subjects with either, neither or both CWP and persistent fatigue based on unadjusted analysis. ANOVA demonstrated statistically significant differences in mean age across the groups, with the fatigue only group having the lowest mean age and the pain only group having the highest mean age. Post hoc analysis with Bonferroni correction showed that there were statistically significant differences between the group with no symptoms and those with either pain or fatigue, and between those with pain only and those with fatigue only, but not for other comparisons (data not shown). Mean BMI was lowest in those with neither pain nor fatigue and highest in those with pain only, and post hoc analysis demonstrated a statistical difference between subjects with neither symptom and subjects with pain only or both, and those with fatigue only and those with pain only or both.

\section{[TABLE 2.]}

Chi square tests demonstrated statistically significant findings for all other characteristics (demographic variables, self-reported chronic disease and psychological factors), with the exception of cancer. For several comparisons (gender, overweight/obese, unemployment, one-person households, weekly exercise, heart disease, arthritis, and psychological factors) there was a trend for the group with both symptoms to be a more extreme version of the groups with one symptom (e.g. 17\% of subjects with both symptoms were 
probable cases of depression, compared to $8 \%$ of those with CWP, $12 \%$ with fatigue and $3 \%$ with neither symptom). The proportion of subjects who reported caring for others was similar in the group with both symptoms (35\%) and those with neither symptom (36\%), lowest in the group with pain only $(27 \%)$ and highest in the group with fatigue only ( $45 \%)$; the proportion with young children showed a similar trend $(18 \%, 18 \%, 11 \%, 28 \%$, respectively). The proportion of responders with only a primary level of education was higher in both the group with pain only (42\%) and the group with both symptoms (35\%) than either responders with fatigue only or neither symptom (both $25 \%$ ). Subjects with either both symptoms, or fatigue only, more often smoked every day $(26 \%, 22 \%)$ than those with pain only $(19 \%)$, or neither symptom (18\%), but were less often consumers of more than 10 units of alcohol per week. For comparisons of asthma and diabetes subjects in the three groups with symptoms were consistently different to subjects in the group with neither symptom.

Table 3 shows the crude and adjusted odds ratios for the association of reporting both symptoms (rather than neither) with BMI, activity levels, perceived ability to influence health and chronic disease. After adjusting for confounders (age, gender, anxiety and depression), odds of reporting both symptoms (rather than neither) were statistically significantly higher in subjects with higher BMI compared to normal or low (OR 1.7, 95\% CI: 1.2, 2.3), being active less than weekly compared to being active weekly (OR 1.5, 95\% CI: 1.1, 2.1), having any chronic disease (OR 3.9. 95\% CI: 2.9, 5.4), and with the perception of not being able to influence health (OR 3.2, 95\% CI: 2.0, 5.1). Reporting both pain and fatigue had strong associations with some specific chronic conditions: heart disease (OR 2.6, 95\% CI 1.6, 4.5); diabetes (OR 2.3, 95\% CI 1.3, 4.0); arthritis (OR 5.0, 95\% CI 3.2, 7.9); fibromyalgia (OR 13, 95\% CI 4.6, 38.4); and cancer, although this association was not statistically significant (OR 2.2, 95\% CI: $0.95,5.27$ ).

\section{[TABLE 3].}

\section{DISCUSSION}

\subsection{Main findings}

Previous work has shown co-occurrence of strictly defined syndromes associated with pain and fatigue, but to our knowledge this study is the first to quantify the co-occurrence of pain and fatigue as symptoms in the general population. Our results demonstrate that the co-occurrence of pain and fatigue is consistently high regardless of age or sex.

Fatigue was reported by $64 \%$ of subjects with limiting widespread pain, compared to $18 \%$ of subjects with no chronic pain. In people with limiting fatigue, $34 \%$ also had limiting widespread pain, compared to $7 \%$ of non-fatigued individuals. Some of the findings may be due to the underlying prevalence of the symptoms alone, that is, the symptoms may have occurred together by chance, and this can be calculated by multiplying the prevalence of one symptom by the other. In this study nearly two times as many women and three and a half times as many men with $\mathrm{CWP}+\mathrm{L}$ reported limiting fatigue as would be expected given the underlying prevalence of the symptoms, and this finding was consistent across all age groups (data not shown, but available from authors). Increased odds of reporting both symptoms were found in subjects with higher BMI, being less active than weekly, having certain chronic diseases (heart disease, diabetes, arthritis) and with the perception of not being able to influence health.

\subsection{Possible explanations for the co-occurrence of pain and fatigue}

In a cross-sectional study it is impossible to determine the direction of causality, if any exists. It is likely that there is more than one explanation for the co-occurrence of pain and fatigue, and indeed the extent to which any one mechanism mediates the co-occurrence in an individual may vary over time. Some chronic diseases can cause both pain and fatigue, such as cancer ([Wagner and Cella, 2004] and [Van den Beukenvan Everdingen et al., 2007]), multiple sclerosis ([O'Connor et al., 2007] and [Putzki et al., 2008]), and arthritis ([Wolfe et al., 1996], [La Montagna et al., 1997], [Peat et al., 2001] and [Grotle et al., 2008]). Although only $25 \%$ of subjects with both symptoms reported such a condition (i.e. cancer or arthritis), any underlying painful chronic condition may account for some of the empirical findings, as fatigue is a common feature of chronic pain (Zautra et al., 2007). A second explanation is that the symptoms are linked as a result of drug side effects, such as opioid analgesics (Ytterberg et al., 1998), agents for neuropathic pain (Kusturica et al., 2002) or inhibitors of angiotensin converting enzyme (Join Formulary Committee, 2008). A third reason for symptom co-reporting is that both pain and fatigue are associated with anxiety or 
depression. Mental health problems are more common in people with widespread pain (Benjamin et al., 2000), fatigue has been reported to be common in people with depression ([Kumar et al., 2004] and [Shiels et al., 2004]) and depressed people more often have high levels of pain (Bair et al., 2003). The odds ratios were attenuated after adjustment for anxiety and depression and residual confounding is possible. It is possible that other psychological factors may explain part of the apparent relationship between self-reported chronic disease and reporting of both symptoms. Processes of somatisation may increase attention to bodily symptoms, and strengthen the attribution of such sensations to physical illness. This could, for example, increase the reporting of fatigue, pain, non-cardiac chest pain, and possibly self-reported heart disease. Fourthly, it is possible that pain and fatigue per se might be directly pathologically linked, and this might be mediated through central sensitisation, resulting from neuroendocrine disturbance (McBeth et al., 2007), which has been proposed as a pathological mechanism responsible for part of both fibromyalgia (Yunus, 2007) and chronic fatigue syndrome (Meeus and Nijs, 2007). Finally, the symptoms may be reported in parallel but not causally linked.

\subsection{Limitations of the study}

The data in this study was based on self-report. We have used components of validated questionnaires to provide data on psychological factors (anxiety, depression and illness perceptions) and have provided full details of questions that were not part of a previously used questionnaire. The assessment of symptoms can only be based on self-report, and we selected questions that have been used in other community-based surveys (e.g. [Pope et al., 1997] and [Papageorgiou et al., 2002]). However, this issue should be considered when interpreting the estimates for the prevalence of chronic disease, and the associations of the symptoms with the chronic diseases. Other investigators have reported similar figures for the prevalence of asthma (5\%, c.f. 8\% Dalstra et al., 2005 and 5\% ([Mohangoo et al., 2006] and [Uijen et al., 2008])), diabetes (5\%, c.f. 3\% Dalstra et al., 2005 and 6.8\% (Bindraban et al., 2008)), heart disease (7\%, c.f. 3.4\% Dalstra et al., $2005))$, cancer ( $2 \%$, c.f. $1.5 \%$ Dalstra et al., 2005)), arthritis (7\%, c.f. $5 \%$ Dalstra et al., 2005)) and fibromyalgia ( $1 \%$ c.f. $2 \%$, Wolfe et al., 1995). Our estimates for the prevalence of symptoms are supported by comparison with the existing literature (discussed below).

\subsection{Comparison to existing literature}

The estimated prevalence of chronic widespread pain in this study (18\%) is higher than other estimates (e.g. 11\% in Croft et al., 1993; 13\% in Hunt et al., 1999). One reason for this might be because the American College of Rheumatology (ACR) definition of chronic widespread pain (Wolfe et al., 1990) was only approximated in this study. In our definition, subjects did not need to have pain in contralateral limbs, as this information was unavailable for the empirical analysis.

The prevalence of persistent fatigue was also higher than other population based estimates (e.g. 18\% in Pawlikowska et al., 1994; 14\% in Lawrie and Pelosi, 1995). This could be because the current study used a temporal element of 3 months, as opposed to the more commonly used 6 months duration. However, this seems unlikely because the prevalence of frequent fatigue lasting 3 months or more $(33 \%)$ was very similar to the prevalence of fatigue lasting 6 months or more (30\%) (Creavin, 2008). Existing literature reveals remarkable consistency in the prevalence of fatigue, even when large differences in the definition exist, for example, Skapinakis et al. (2003) reported that the prevalence of fatigue lasting 1 month or more was 15\%, which is similar to the figure of $11.5 \%$ reported by David et al. (1990) for fatigue lasting 3 months or more, and the $11.3 \%$ reported by Wessely et al. (1996) for fatigue lasting 6 months or more. The definition of persistent fatigue was less restrictive than previous definitions of fatigue, most notably that for chronic fatigue syndrome (Fukuda et al., 1994), and therefore we suggest that other differences in definition (or selective non-response, discussed below) may explain the higher estimates reported here.

The degree of symptom co-occurrence is supported by the work of others who have demonstrated that fatigue is more common in people with chronic widespread pain than those without pain (Croft et al., 1993) and that there is more pain in people with more severe fatigue than less severe fatigue (Njoku et al., 2007).

\subsection{Response rate and generalizability of findings}

The response rate for the survey was less than desired, despite following measures which have been suggested to increase response (Edwards et al., 2002). Other community studies investigating the prevalence of pain or fatigue have also reported response rates below 65\% (Pawlikowska et al., 1994: 48.3\% (64\% after adjustments); Picavet and Schouten, 2003: 46.9\%; Huibers et al., 2004: 45\%). We used several methods to estimate the potential influence of non-response on our findings in particular regarding estimates of the prevalence of symptoms. Compared to the Dutch population (Statistics Netherlands, 2008) 
the study sample was largely similar with comparable levels of chronic disease, but had a higher proportion of females, older people, one-person households and unemployed people. Selective non-response of healthy individuals may have resulted in an overestimation of the prevalence of chronic widespread pain and persistent fatigue, assuming that non-responders were more likely to be without these symptoms. In this study, $29 \%$ of non-responding subjects who gave a reason for non-participation indicated that they had no health problems. Analyses of response to subsequent mailings showed that there might be some selective non-response of persons with more anxiety or depression, but the number and severity of symptoms were similar in early and late responders (Van der Windt et al., 2008). In a sensitivity analysis, if all nonresponders were free of CWP and persistent fatigue then in a sample of 4741 people, chronic widespread pain would be found in 451 and persistent fatigue would be found in 809 , giving prevalences of $10 \%$ and 17\%, respectively, close to previously reported estimates ([Croft et al., 1993], [Pawlikowska et al., 1994], [Lawrie and Pelosi, 1995] and [Hunt et al., 1999]).

\subsection{Implications and further work}

It is likely that more than one explanation connects the symptoms and further work could investigate the extent to which each of these mechanisms mediate the co-occurrence of the symptoms. It would also be helpful to investigate the interactions between pain and fatigue over time, particularly to determine in which people the symptoms progress to functional syndromes, and how this progression occurs. This may help in the early identification of individuals with poor outcome, and may help to develop more successful, targeted interventions for pain and fatigue. It will be important to carry out such research in communitybased or primary care populations if the aim is to prevent chronic symptoms and related disability, rather than to focus on management of chronic functional syndromes.

The finding that perceived ability to influence health was strongly associated with reporting both symptoms also deserves further investigation. Personal control or self efficacy has previously been found to be associated with a poorer outcome for fatigue (Ray et al., 1997), and greater pain-related disability (Asghari and Nicholas, 2001) and may have additional associations with depressive symptoms, employment status and pain distribution (Rahman et al., 2004). Patients who have additional symptoms, (i.e. both pain and fatigue rather than one symptom alone), may have greater disease severity, either perceived or actual, and this may affect their self efficacy. The perception of being unable to influence health may be related to an increased tendency to report symptoms (making co-occurrence more likely to be reported), or be a valid perception that results from severe and disabling symptoms. Additionally, perceived ability to influence health may be partly responsible for the other associations that were noted, as perceptions have previously been shown to be associated with being physically active (Gillis, 1993), which in turn is known to be related to BMI (Murphy et al., 2007) and therefore diabetes (Manson et al., 1992), heart disease (Manson et al., 1999), and arthritis (Sahyoun et al., 1999).

Pain and fatigue are very common symptoms in the general population and are often limiting in nature. Co-reporting of the symptoms is common, and happens more often than expected by chance, especially in those with more severe symptoms. Reporting both symptoms is associated with high BMI, low levels of activity and not perceiving the ability to influence health. Additional associations exist with chronic disease, anxiety, and depression. Clinicians should be aware that pain and fatigue often co-occur, particularly in people with high BMI and chronic disease, and should be alert for anxiety and depression in patients who report both symptoms.

\section{ACKNOWLEDGEMENTS}

Dr. George Peat provided some advice on the statistical analysis. The authors thank the doctors, staff and patients of the participating general practices.

\section{REFERENCES}

Aaron et al., 2002 L.A. Aaron, L.M. Arguelles, S. Ashton, M. Belcourt, R. Herrell and J. Goldberg et al., Health and functional status of twins with chronic regional and widespread pain, J Rheumatol 29 (2002), pp. 2426-2434. View Record in Scopus | Cited By in Scopus (6)

Asghari and Nicholas, 2001 A. Asghari and M.K. Nicholas, Pain self-efficacy beliefs and pain behaviour. A prospective study, Pain 94 (2001), pp. 85-100.

Bair et al., 2003 M.J. Bair, R.L. Robinson, W. Katon and K. Kroenke, Depression and pain comorbidity: a literature review, Arch Int Med 163 (2003), pp. 2433-2445. 
Creavin, S.T., Dunn, K.M., Mallen, C.D., Nijrolder, I., Windt, D.A.W.M. van der. Co-occurrence and associatiof of pain and fatigue in a community sample of Dutch adults. European Journal of Pain: 2010, 14(3), 327-354

Barry et al., 2003 L.C. Barry, Z. Guo, R.D. Kerns, B.D. Duong and M.C. Reid, Functional self-efficacy and pain-related disability among older veterans with chronic pain in a primary care setting, Pain 104 (1-2) (2003), pp. 131-713.

Benjamin et al., 2000 S. Benjamin, S. Morris, J. McBeth, G.J. Macfarlane and A.J. Silman, The association between chronic widespread pain and mental disorder: a population-based study, Arthritis Rheum 43 (2000), pp. 561-567.

Bierl et al., 2004 C. Bierl, R. Nisenbaum, D.C. Hoaglin, B. Randall, A.B. Jones and E.R. Unger et al., Regional distribution of fatiguing illnesses in the United States: a pilot study, Popul Health Metr 2 (2004), p. 1.

Bindraban et al., 2008 N.R. Bindraban, I.G. van Valkengoed, G. Mairuhu, F. Holleman, J.B. Hoekstra and B.P. Michels et al., Prevalence of diabetes mellitus and the performance of a risk score among Hindustani Surinamese, African Surinamese and ethnic Dutch: a cross-sectional population-based study, BMC Public Health 8 (August 1) (2008), p. 271.

Buchwald and Garrity, 1994 D. Buchwald and D. Garrity, Comparison of patients with chronic fatigue syndrome, fibromyalgia, and multiple chemical sensitivities, Arch Int Med 154 (1994), pp. $2049-2053$.

Creavin, 2008 Creavin ST. Prevalence and characteristics of pain, fatigue, and combinations of these symptoms: a cross-sectional survey and follow-up study [thesis]. Keele University; 2008.

Croft et al., 1993 P. Croft, A.S. Rigby, R. Boswell, J. Schollum and A. Silman, The prevalence of chronic widespread pain in the general population, J Rheumatol 20 (1993), pp. 710-713.

Dalstra et al., 2005 J.A. Dalstra, A.E. Kunst, C. Borrell, E. Breeze, E. Cambois and G. Costa et al., Socioeconomic differences in the prevalence of common chronic diseases: an overview of eight European countries, Int J Epidemiol 34 (2005), pp. 316-326.

David et al., 1990 A. David, A. Pelosi, E. McDonald, D. Stephens, D. Ledger and R. Rathbone et al., Tired, weak, or in need of rest: fatigue among general practice attenders, BMJ 301 (6762) (1990), pp. 11991202.

Edwards et al., 2002 P. Edwards, I. Roberts, M. Clarke, C. DiGuiseppi, S. Pratap and R. Wentz et al., Increasing response rates to postal questionnaires: systematic review, BMJ 324 (2002), p. 1183.

Evengard et al., 2005 B. Evengard, A. Jacks, N.L. Pedersen and P.F. Sullivan, The epidemiology of chronic fatigue in the Swedish Twin Registry, Psychol Med 35 (2005), pp. 1317-1326.

Fukuda et al., 1994 K. Fukuda, S.E. Straus, I. Hickie, M.C. Sharpe, J.G. Dobbins and A. Komaroff, The chronic fatigue syndrome: a comprehensive approach to its definition and study. International Chronic Fatigue Syndrome Study Group, Ann Int Med 121 (1994), pp. 953-959.

Gillis, 1993 A.J. Gillis, Determinants of a health-promoting lifestyle: an integrative review, J Adv Nurs 18 (1993), pp. 345-353.

Grotle et al., 2008 M. Grotle, K.B. Hagen, B. Natvig, F.A. Dahl and T.K. Kvien, Prevalence and burden of osteoarthritis: results from a population survey in norway, J Rheumatol 35 (2008), pp. 677-684.

Hamilton et al., 2001 W.T. Hamilton, G.H. Hall and A.P. Round, Frequency of attendance in general practice and symptoms before development of chronic fatigue syndrome: a case-control study, Brit J Gen Pract 51 (2001), pp. 553-558.

Hickie et al., 2002 I. Hickie, T. Davenport, C. Issakidis and G. Andrews, Neurasthenia: prevalence, disability and health care characteristics in the Australian community, Brit J Psychiatry 181 (2002), pp. 56-61.

Hudson et al., 1992 J.I. Hudson, D.L. Goldenberg, H.G. Pope Jr., P.E. Keck Jr. and L. Schlesinger, Comorbidity of fibromyalgia with medical and psychiatric disorders, Am J Med 92 (1992), pp. 363-367. Huibers et al., 2004 M.J. Huibers, I.J. Kant, G.M. Swaen and S.V. Kasl, Prevalence of chronic fatigue syndrome-like caseness in the working population: results from the Maastricht cohort study, Occup Environ Med 61 (2004), pp. 464-466.

Hunt et al., 1999 I.M. Hunt, A.J. Silman, S. Benjamin, J. McBeth and G.J. Macfarlane, The prevalence and associated features of chronic widespread pain in the community using the 'Manchester' definition of chronic widespread pain, Rheumatology 38 (1999), pp. 275-279 (Oxford).

IASP, 1986 International Association for the Study of Pain, Subcommittee on taxonomy classification of chronic pain. Descriptions of chronic pain syndromes and definitions of pain terms, Pain 3 (Suppl.) (1) (1986), p. S1-226.

Jason et al., 2000 L.A. Jason, R.R. Taylor and C.L. Kennedy, Chronic fatigue syndrome, fibromyalgia, and multiple chemical sensitivities in a community-based sample of persons with chronic fatigue syndrome-like symptoms, Psychosom Med 62 (2000), pp. 655-663.

Joint Formulary Committee, 2008 Joint Formulary Committee. British National Formulary. London: British Medical Association and Royal Pharmaceutical Society of Great Britain; 2008.

Kadam et al., 2005 U.T. Kadam, E. Thomas and P.R. Croft, Is chronic widespread pain a predictor of allcause morbidity? A 3 year prospective population-based study in family practice, J Rheumatol 32 (2005), pp. 1341-1348. 
Kato et al., 2006 K. Kato, P.F. Sullivan, B. Evengard and N.L. Pedersen, Chronic widespread pain and its comorbidities: a population-based study, Arch Int Med 166 (2006), pp. 1649-1654.

Kenter et al., 2003 E.G. Kenter, I.M. Okkes, S.K. Oskam and H. Lamberts, Tiredness in Dutch family practice. Data on patients complaining of and/or diagnosed with "tiredness", Fam Pract 20 (2003), pp. 434-440.

Kroenke et al., 1988 K. Kroenke, D.R. Wood, A.D. Mangelsdorff, N.J. Meier and J.B. Powell, Chronic fatigue in primary care. Prevalence, patient characteristics, and outcome, JAMA 260 (1988), pp. 929-934.

Kumar et al., 2004 A. Kumar, S. Clark, E.D. Boudreaux and C.A. Camargo Jr, A multicenter study of depression among emergency department patients, Acad Emerg Med 11 (2004), pp. 1284-1289.

Kusturica et al., 2002 J. Kusturica, I. Zulic, S. Loga-Zec, N. Mulabegovic, S. Loga and E. Kapic, Frequency and characteristics of side effects associated with antidepressant drugs, Bosn J Basic Med Sci 2 (2002), pp. 5-11.

La Montagna et al., 1997 G. La Montagna, R. Tirri, A. Baruffo, B. Preti and S. Viaggi, Clinical pattern of pain in rheumatoid arthritis, Clin Exp Rheumatol 15 (1997), pp. 481-485.

Lawrie and Pelosi, 1995 S.M. Lawrie and A.J. Pelosi, Chronic fatigue syndrome in the community. Prevalence and associations, Brit J Psychiatry 166 (1995), pp. 793-797.

Macfarlane et al., 2008 G.J. Macfarlane, G. Norrie, K. Atherton, C. Power and G.T. Jones, The influence of socio-economic status on the reporting of regional and widespread musculoskeletal pain: results from the 1958 British birth Cohort study, Ann Rheum Dis (October 24) (2008) .

Manson et al., 1992 J.E. Manson, D.M. Nathan, A.S. Krolewski, M.J. Stampfer, W.C. Willett and C.H. Hennekens, A prospective study of exercise and incidence of diabetes among US male physicians, JAMA 268 (1992), pp. 63-67.

Manson et al., 1999 J.E. Manson, F.B. Hu, J.W. Rich-Edwards, G.A. Colditz, M.J. Stampfer and W.C. Willett et al., A prospective study of walking as compared with vigorous exercise in the prevention of coronary heart disease in women, N Engl J Med 341 (1999), pp. 650-658.

McBeth et al., 2007 J. McBeth, A.J. Silman, A. Gupta, Y.H. Chiu, D. Ray and R. Morriss et al., Moderation of psychosocial risk factors through dysfunction of the hypothalamic-pituitary-adrenal stress axis in the onset of chronic widespread musculoskeletal pain: findings of a population-based prospective cohort study, Arthritis Rheum 56 (2007), pp. 360-371.

Meeus and Nijs, 2007 M. Meeus and J. Nijs, Central sensitization: a biopsychosocial explanation for chronic widespread pain in patients with fibromyalgia and chronic fatigue syndrome, Clin Rheumatol 26 (2007), pp. 465-473.

Moss-Morris et al., 2002 R. Moss-Morris, J. Weinman, K. Petrie, R. Horne, L. Cameron and D. Buick, The revised illness perception questionnaire (IPQ-R), Psychol Health 17 (2002), pp. 1-16.

Mohangoo et al., 2006 A.D. Mohangoo, M.W. van der Linden, F.G. Schellevis and H. Raat, Prevalence estimates of asthma or COPD from a health interview survey and from general practitioner registration: what's the difference?, Eur J Public Health 16 (2006), pp. 101-105.

Murphy et al., 2007 M.H. Murphy, A.M. Nevill, E.M. Murtagh and R.L. Holder, The effect of walking on fitness, fatness and resting blood pressure: a meta-analysis of randomised, controlled trials, Prev Med 44 (2007), pp. 377-385.

Njoku et al., 2007 M.G. Njoku, L.A. Jason and S.R. Torres-Harding, The prevalence of chronic fatigue syndrome in Nigeria, J Health Psychol 12 (2007), pp. 461-474.

O'Connor et al., 2007 A.B. O'Connor, S.R. Schwid, D.N. Herrmann, J.D. Markman and R.H. Dworkin, Pain associated with multiple sclerosis: Systematic review and proposed classification, Pain (2007).

Papageorgiou et al., 2002 A.C. Papageorgiou, A.J. Silman and G.J. Macfarlane, Chronic widespread pain in the population: a seven year follow-up study, Ann Rheum Dis 61 (2002), pp. 1071-1074.

Pawlikowska et al., 1994 T. Pawlikowska, T. Chalder, S.R. Hirsch, P. Wallace, D.J. Wright and S.C. Wessely, Population based study of fatigue and psychological distress, BMJ 308 (1994), pp. 763-766.

Peat et al., 2001 G. Peat, R. McCarney and P. Croft, Knee pain and osteoarthritis in older adults: a review of community burden and current use of primary health care, Ann Rheum Dis 60 (2001), pp. 91-97.

Picavet and Schouten, 2003 H.S.J. Picavet and J.S.A.G. Schouten, Musculoskeletal pain in the Netherlands: prevalences, consequences, and risk groups, the DMC3-study, Pain 102 (2003), pp. 167178. )

Pope et al., 1997 D.P. Pope, P.R. Croft, C.M. Pritchard and A.J. Silman, Prevalence of Shoulder Pain in the Community: the influence of case definition, Ann Rheum Dis 56 (1997), pp. 308-312. Full Text via CrossRef | View Record in Scopus | Cited By in Scopus (80)

Putzki et al., 2008 N. Putzki, Z. Katsarava, S. Vago, H.C. Diener and V. Limmroth, Prevalence and severity of multiple-sclerosis-associated fatigue in treated and untreated patients, Eur Neurol 59 (2008), pp. 136142.

Rahman et al., 2004 A. Rahman, G. Ambler, M.R. Underwood and M.E. Shipley, Important determinants of self-efficacy in patients with chronic musculoskeletal pain, J Rheumatol 31 (2004), pp. 1187-1192. 
Creavin, S.T., Dunn, K.M., Mallen, C.D., Nijrolder, I., Windt, D.A.W.M. van der. Co-occurrence and association of pain and fatigue in a community sample of Dutch adults. European Journal of Pain: 2010, 14(3), 327-354

Ray et al., 1997 C. Ray, S. Jefferies and W.R. Weir, Coping and other predictors of outcome in chronic fatigue syndrome: a 1-year follow-up, J Psychosom Res 43 (1997), pp. 405-415.

Reeves et al., 2003 W.C. Reeves, A. Lloyd, S.D. Vernon, N. Klimas, L.A. Jason and G. Bleijenberg et al., Identification of ambiguities in the 1994 chronic fatigue syndrome research case definition,

recommendations for resolution, BMC Health Serv Res 3 (2003), p. 25.

Reyes et al., 2003 M. Reyes, R. Nisenbaum, D.C. Hoaglin, E.R. Unger, C. Emmons and B. Randall et al., Prevalence and incidence of chronic fatigue syndrome in Wichita, Kansas, Arch Intern Med 163 (2003), pp. 1530-1536.

Sahyoun et al., 1999 N.R. Sahyoun, M.C. Hochberg, C.G. Helmick, T. Harris and E.R. Pamuk, Body mass index, weight change, and incidence of self-reported physician-diagnosed arthritis among women, Am J Public Health 89 (1999), pp. 391-394.

Schochat and Raspe, 2003 T. Schochat and H. Raspe, Elements of fibromyalgia in an open population, Rheumatology 42 (2003), pp. 829-835 (Oxford).

Schur et al., 2007 E.A. Schur, N. Afari, H. Furberg, M. Olarte, J. Goldberg and P.F. Sullivan et al., Feeling bad in more ways than one: comorbidity patterns of medically unexplained and psychiatric conditions, J Gen Int Med 22 (2007), pp. 818-821.

Schweitzer et al., 1995 R. Schweitzer, B. Kelly, A. Foran, D. Terry and J. Whiting, Quality of life in chronic fatigue syndrome, Soc Sci Med 41 (1995), pp. 1367-1372.

Shiels et al., 2004 C. Shiels, M. Gabbay, C. Dowrick and C. Hulbert, Depression in men attending a rural general practice. Factors associated with prevalence of depressive symptoms and diagnosis, Brit J Psychiatry 185 (2004), pp. 239-244.

Skapinakis et al., 2000 P. Skapinakis, G. Lewis and H. Meltzer, Clarifying the relationship between unexplained chronic fatigue and psychiatric morbidity: results from a community survey in Great Britain, Am J Psychiatry 157 (2000), pp. 1492-1498.

Skapinakis et al., 2003 P. Skapinakis, G. Lewis and V. Mavreas, Cross-cultural differences in the epidemiology of unexplained fatigue syndromes in primary care, Brit J Psych 182 (2003), pp. 205-209.

Statistics Netherlands, 2008 Statistics Netherlands; 2008. <http://statline.cbs.nl/>.

Thomas et al., 2004 E. Thomas, R. Wilkie, G. Peat, S. Hill, K. Dziedzic and P. Croft, The North Staffordshire Osteoarthritis Project-NorStOP: prospective, 3-year study of the epidemiology and management of clinical osteoarthritis in a general population of older adults, BMC Musculoskelet Disord 5 (January 13) (2004), pp. 2-9.

Turner et al., 2005 J.A. Turner, M. Ersek and C. Kemp, Self-efficacy for managing pain is associated with disability, depression, and pain coping among retirement community residents with chronic pain, J Pain 6 (7) (2005), pp. 471-479.

Uijen et al., 2008 A.A. Uijen, T.R. Schermer, H.J. van den Hoogen, J. Mulder, E.M. Zantinge and B.J. Bottema, Prevalence of and health care consumption for asthma and COPD in relation to ethnicity, Ned Tijdschr Geneeskd 152 (20) (2008), pp. 1157-1163 (in Dutch).

Van den Beuken-van Everdingen et al., 2007 M.H. Van den Beuken-van Everdingen, J.M. de Rijke, A.G. Kessels, H.C. Schouten, K.M. van and J. Patijn, Prevalence of pain in patients with cancer: a systematic review of the past 40 years, Ann Oncol 18 (2007), pp. 1437-1449.

Van der Windt et al., 2008 D.A. Van der Windt, K.M. Dunn, M.N. Spies-Dorgelo, C.D. Mallen, A.H. Blankenstein and W.A. Stalman, Impact of physical symptoms on perceived health in the community, J Psychosom Res 64 (2008), pp. 265-274.

Wagner and Cella, 2004 L.I. Wagner and D. Cella, Fatigue and cancer: causes, prevalence and treatment approaches, Brit J Cancer 91 (2004), pp. 822-828.

Wessely et al., 1996 S. Wessely, T. Chalder, S. Hirsch, P. Wallace and D. Wright, Psychological symptoms, somatic symptoms, and psychiatric disorder in chronic fatigue and chronic fatigue syndrome: a prospective study in the primary care setting, Am J Psych 153 (8) (1996), pp. 1050-1059.

Wessely et al., 1997 S. Wessely, T. Chalder, S. Hirsch, P. Wallace and D. Wright, The prevalence and morbidity of chronic fatigue and chronic fatigue syndrome: a prospective primary care study, Am J Public Health 87 (1997), pp. 1449-1455.

White and Thompson, 2003 K.P. White and J. Thompson, Fibromyalgia syndrome in an Amish community: a controlled study to determine disease and symptom prevalence, J Rheumatol 30 (2003), pp. 18351840.

Wolfe et al., 1990 F. Wolfe, H.A. Smythe, M.B. Yunus, R.M. Bennett, C. Bombardier and D.L. Goldenberg et al., The American College of Rheumatology 1990 Criteria for the Classification of Fibromyalgia. Report of the Multicenter Criteria Committee, Arthritis Rheum 33 (1990), pp. 160-172.

Wolfe et al., 1995 F. Wolfe, K. Ross, J. Anderson, I.J. Russell and L. Hebert, The prevalence and characteristics of fibromyalgia in the general population, Arthritis Rheum 38 (1995), pp. 19-28.

Wolfe et al., 1996 F. Wolfe, D.J. Hawley and K. Wilson, The prevalence and meaning of fatigue in rheumatic disease, J Rheumatol 23 (1996), pp. 1407-1417. 
Creavin, S.T., Dunn, K.M., Mallen, C.D., Nijrolder, I., Windt, D.A.W.M. van der. Co-occurrence and association of pain and fatigue in a community sample of Dutch adults. European Journal of Pain: 2010, 14(3), 327-354

Ytterberg et al., 1998 S.R. Ytterberg, M.L. Mahowald and S.R. Woods, Codeine and oxycodone use in patients with chronic rheumatic disease pain, Arthritis Rheum 41 (1998), pp. 1603-1612.

Yunus, 2007 M.B. Yunus, Fibromyalgia and overlapping disorders: the unifying concept of central sensitivity syndromes, Semin Arthritis Rheum 36 (2007), pp. 339-356.

Zautra et al., 2007 A.J. Zautra, R. Fasman, B.P. Parish and M.C. Davis, Daily fatigue in patients with osteoarthritis, rheumatoid arthritis and fibromyalgia, Pain 128 (2007), pp. 128-135.

Zigmund and Snaith, 1983 A.S. Zigmund and R.P. Snaith, The hospital anxiety and depression scale, Acta Psychiat Scand 67 (1983), pp. 361-370.

\section{TABLES AND FigURES}

Table 1: Empirical definitions of pain and fatigue.

\begin{tabular}{|c|c|}
\hline Definition & \\
\hline Chronic regional pain & $\begin{array}{l}\text { Pain in the last month and also pain lasting at least } 3 \text { months in at } \\
\text { least one of seven locations }\end{array}$ \\
\hline $\begin{array}{l}\text { Non-limiting chronic } \\
\text { widespread pain (CWP-L) }\end{array}$ & $\begin{array}{l}\text { Pain in the last month and also pain lasting at least } 3 \text { months in each } \\
\text { of upper limb, lower limb and axial pain }\end{array}$ \\
\hline $\begin{array}{l}\text { Limiting chronic widespread } \\
\text { pain }(\mathrm{CWP}+\mathrm{L})\end{array}$ & $\begin{array}{l}\text { As CWP-L and additionally limited by their pain in two of the three } \\
\text { anatomical sites on at least } 5 \text { days per month }\end{array}$ \\
\hline $\begin{array}{l}\text { Non limiting persistent fatigue } \\
(\mathrm{PF})\end{array}$ & $\begin{array}{l}\text { Fatigue in the last month and also fatigue lasting } 3 \text { months or more } \\
\text { and occurring on at least } 5 \text { days per month }\end{array}$ \\
\hline $\begin{array}{l}\text { Limiting persistent fatigue } \\
(\mathrm{PF}+\mathrm{L})\end{array}$ & $\begin{array}{l}\text { As PF and additionally limited by their fatigue on at least } 5 \text { days per } \\
\text { month }\end{array}$ \\
\hline
\end{tabular}

Fig. 1. Co-occurrence of pain and fatigue stratified by gender.

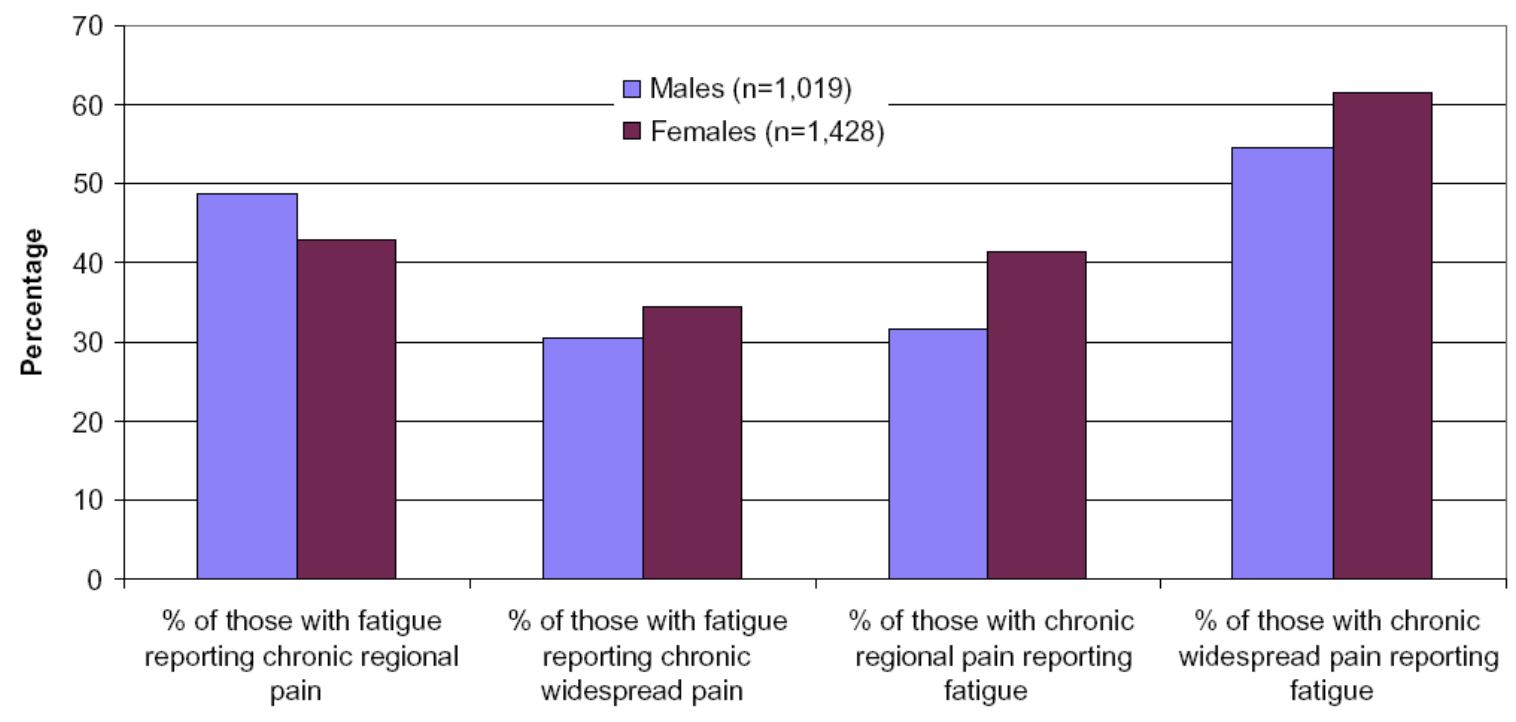

Symptom combination 
Fig. 2. Co-occurrence of pain and fatigue in different age groups.

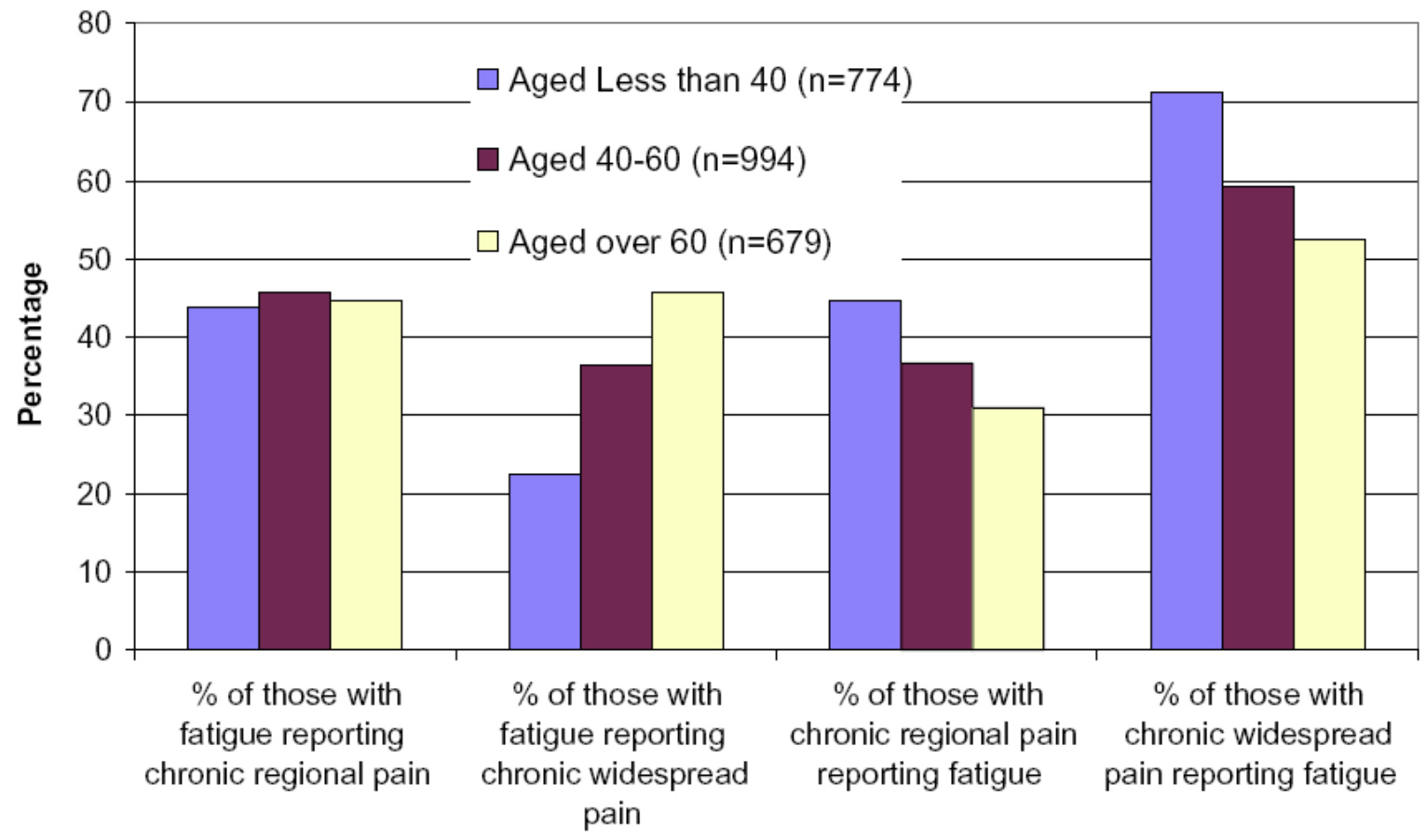

Symptom combination

Table 2: Characteristics of responders with pain and fatigue, alone and in combination $(n=2447 \mathrm{a})$, figures are $\%(n)$, unless indicated otherwise.

\begin{tabular}{|l|l|l|l|l|l|}
\hline & $\begin{array}{l}\text { Neither } \\
(\mathbf{n}=\mathbf{1 4 5 5})\end{array}$ & $\begin{array}{l}\text { Fatigue } \\
\text { only } \\
(\mathbf{n = 5 4 1 )}\end{array}$ & $\begin{array}{l}\text { Pain only } \\
(\mathbf{n = 1 8 3})\end{array}$ & $\begin{array}{l}\text { Pain and } \\
\text { fatigue } \\
\mathbf{( n = 2 6 8 )}\end{array}$ & Pb \\
\hline Female & $51.8(753)$ & $67.5(365)$ & $65.0(119)$ & $71.3(191)$ & $<0.001$ \\
\hline Mean age (SD) & $49.9(16.4)$ & $46.9(16.1)$ & $56.0(13.6)$ & $52.2(14.8)$ & $<0.001$ \\
\hline Mean BMI (SD) & $25.4(4.2)$ & $25.6(6.1)$ & $27.1(14.6)$ & $27.0(5.0)$ & $<0.001$ \\
\hline Overweight or obese & & & & & \\
\hline (BMI $\geq 25)$ & $48.5(682)$ & $47.1(245)$ & $55.1(97)$ & $62.8(162)$ & $<0.001$ \\
\hline Unemployedc & $6.3(92)$ & $15.0(80)$ & $15.4(28)$ & $31.9(85)$ & $<0.001$ \\
\hline One person household & $18.6(270)$ & $17.7(96)$ & $23.0(42)$ & $25.4(68)$ & $<0.001$ \\
\hline Care for others & $35.6(518)$ & $45.2(244)$ & $26.8(49)$ & $35.0(93)$ & $<0.001$ \\
\hline Children aged $<5$ years old & $18.2(204)$ & $28.1(114)$ & $10.6(15)$ & $17.6(30)$ & $<0.001$ \\
\hline Education: primary only & $25.1(363)$ & $24.8(134)$ & $41.8(76)$ & $35.0(93)$ & $<0.001$ \\
\hline Education: college or & $38.3(555)$ & $39.4(213)$ & $25.3(46)$ & $22.2(59)$ & $<0.001$ \\
\hline
\end{tabular}


Creavin, S.T., Dunn, K.M., Mallen, C.D., Nijrolder, I., Windt, D.A.W.M. van der. Co-occurrence and association of pain and fatigue in a community sample of Dutch adults. European Journal of Pain: 2010, 14(3), 327-354

\begin{tabular}{|c|c|c|c|c|c|}
\hline & $\begin{array}{l}\text { Neither } \\
(\mathrm{n}=1455)\end{array}$ & $\begin{array}{l}\text { Fatigue } \\
\text { only } \\
(n=541)\end{array}$ & $\begin{array}{l}\text { Pain only } \\
(n=183)\end{array}$ & $\begin{array}{l}\text { Pain and } \\
\text { fatigue } \\
(\mathbf{n}=268)\end{array}$ & $\mathbf{P b}$ \\
\hline \multicolumn{6}{|l|}{ university } \\
\hline Exercise weekly & $53.7(782)$ & $45.8(248)$ & $50.3(92)$ & $39.2(105)$ & $<0.001$ \\
\hline Smoke everyday & $17.9(260)$ & $22.4(121)$ & $19.2(35)$ & $25.6(68)$ & 0.036 \\
\hline$>10$ units alcohol per week & $16.3(236)$ & $11.8(63)$ & $20.3(37)$ & $11.7(31)$ & $<0.001$ \\
\hline \multicolumn{6}{|l|}{ Self-reported chronic disease } \\
\hline Asthma & $4.1(59)$ & $8.3(45)$ & $7.7(14)$ & $7.5(20)$ & 0.001 \\
\hline Heart disease & $4.8(70)$ & $9.8(53)$ & $7.1(13)$ & $12.3(33)$ & $<0.001$ \\
\hline Diabetes & $3.7(54)$ & $6.5(35)$ & $8.7(16)$ & $8.6(23)$ & $<0.001$ \\
\hline Cancer & $1.7(25)$ & $2.4(13)$ & $1.6(3)$ & $3.4(9)$ & 0.316 \\
\hline $\begin{array}{l}\text { Rheumatoid Arthritis or } \\
\text { osteoarthritis }\end{array}$ & $4.6(67)$ & $5.0(27)$ & $20.2(37)$ & $21.3(57)$ & $<0.001$ \\
\hline Fibromyalgia & $0.4(6)$ & $0.2(1)$ & $3.8(7)$ & $6.3(17)$ & $<0.001$ \\
\hline No chronic disease & $76.2(1104)$ & $66.9(362)$ & $51.9(95)$ & $42.2(113)$ & $<0.001$ \\
\hline \multicolumn{6}{|l|}{ Psychological factors } \\
\hline $\begin{array}{l}\text { Illness perception: can } \\
\text { influence health (largely/fully } \\
\text { disagree) }\end{array}$ & $5.9(85)$ & $8.4(45)$ & $9.9(18)$ & $17.5(46)$ & $<0.001$ \\
\hline $\begin{array}{l}\text { Anxiety, probable } \\
(\text { HADS }>10)\end{array}$ & $3.8(54)$ & $16.4(88)$ & $10.0(18)$ & $27.2(72)$ & $<0.001$ \\
\hline $\begin{array}{l}\text { Depression, probable } \\
(\text { HADS }>10)\end{array}$ & $2.6(37)$ & $11.7(63)$ & $8.3(15)$ & $17.3(46)$ & $<0.001$ \\
\hline
\end{tabular}

a Figures are subject to missing data $(<5 \%$ per variable) and are given as percentage of column total. b ANOVA for continuous variables (age and BMI), Chi squared for categorical variables (all others).

c Unemployed: figure given include both "unemployed" and receiving "disability benefit". 
Table 3: Odds ratios (and 95\% confidence intervals) for the association of BMI, activity, illness perception and chronic disease with reporting both pain and fatigue $(\mathrm{n}=268 \mathrm{a})$ compared to neither symptom $(\mathrm{n}=1455 \mathrm{a})$.

\begin{tabular}{|c|c|c|c|c|}
\hline Factor & & $\mathbf{R}^{2}$ & $\begin{array}{l}\text { Crude OR (95\% } \\
\text { CI) }\end{array}$ & $\begin{array}{l}\text { Adjusted }{ }^{\mathrm{b}} \text { OR (95\% } \\
\text { CI) }\end{array}$ \\
\hline BMI & $\geq 25$ vs. $<25$ & 0.02 & $1.79(1.37,2.36)$ & $1.67(1.22,2.28)$ \\
\hline Activity & $\begin{array}{l}\text { Less than weekly vs. at least } \\
\text { weekly }\end{array}$ & 0.02 & $1.80(1.38,2.35)$ & $1.52(1.13,2.05)$ \\
\hline \multirow[t]{2}{*}{$\begin{array}{l}\text { Illness } \\
\text { perception }\end{array}$} & Do not know vs. agree & 0.08 & $3.14(2.30,4.29)$ & $2.13(1.49,3.05)$ \\
\hline & Disagree vs. agree & 0.08 & $4.52(3.03,6.74)$ & $3.23(2.03,5.13)$ \\
\hline \multirow[t]{7}{*}{$\begin{array}{l}\text { Chronic } \\
\text { disease }\end{array}$} & Asthma & 0.01 & $1.90(1.13,3.22)$ & $1.49(0.82,2.70)$ \\
\hline & Heart disease & 0.02 & $2.77(1.79,4.28)$ & $2.64(1.56,4.46)$ \\
\hline & Diabetes & 0.01 & $2.43(1.46,4.03)$ & $2.26(1.27,4.01)$ \\
\hline & Cancer & 0.00 & $1.98(0.91,4.29)$ & $2.24(0.95,5.27)$ \\
\hline & $\begin{array}{l}\text { Arthritis (rheumatoid or } \\
\text { osteoarthritis) }\end{array}$ & 0.07 & $5.57(3.80,8.16)$ & $5.04(3.21,7.92)$ \\
\hline & Fibromyalgia & 0.04 & $\begin{array}{l}16.29(6.36 \\
41.71)\end{array}$ & $13.22(4.56,38.36)$ \\
\hline & Any chronic disease & 0.11 & $4.39(3.35,5.76)$ & $3.93(2.87,5.40)$ \\
\hline
\end{tabular}

${ }^{\mathrm{a}}$ Maximum group size. Subject to missing data.

${ }^{\mathrm{b}}$ Adjusted for age, sex, anxiety and depression. 